\title{
The Praxis of Mathematics Teaching: Developing Mathematical Identities
}

\author{
Mathematics teaching as praxis recognizes that teachers are required to \\ continually make morally-dense and value-laden decisions about their work. \\ However, mathematics teachers' practice is constrained by the practice \\ architectures of their field. Therefore, to facilitate effective mathematics \\ pedagogy, it is not enough to attend only to the teachers' practices without also \\ working to reform the practice architectures within which they work. In this \\ paper, data from interviews and observations with effective mathematics teachers \\ are used to identify and explore aspects of classroom practice where students' \\ broader mathematical identities are engaged. A praxis lens is employed to \\ examine these aspects and discuss the moral and ethical dimensions of the \\ teacher's decisions and actions, highlighting the implications for the development \\ of students' mathematical identities. Finally, the data is examined to identify \\ practice architectures that enhance or constrain the teacher's capacity for praxis \\ and the student's opportunities to develop robust mathematical identities.
}

\section{Introduction}

Teachers in mathematics classrooms play a critical role in developing students' mathematical identities (Hayes, Mills, Christie \& Lingard, 2006), but historically many students have left school with debilitating views of the subject. From a pedagogical perspective it is important that teachers are knowledgeable and skilful practitioners, but good mathematics teaching is more than knowledge and technique - it is a form of praxis. Praxis is a particular kind of practice that emphasises the moral, ethical and caring dimensions of teaching. A praxis-oriented teacher is aware that he or she continually makes pedagogical decisions that are morally informed and value-laden and that all learning occurs in relationship with others (Kemmis \& Smith, 2008). A teacher’s praxis, particularly in mathematics education, is an under-researched phenomenon, but one that can have a significant influence on the development of students' identities and how they perceive mathematics at all levels of education. 
In this article the term 'identity' has been used to encompass the broader learning and development that occurs in mathematics classrooms. While learning mathematical skills and knowledge, students are also developing beliefs and attitudes about the subject, and themselves as mathematical learners and practitioners. The term ‘identity’ is problematic and variously defined (Grootenboer, Smith \& Lowrie, 2006), but here we are using it to simply refer to all-round development, particularly in mathematics (i.e., their mathematical identity). ${ }^{1}$ This includes development in their mathematical knowledge and skills, but also affective qualities such as beliefs, values and attitudes (Zevenbergen \& Grootenboer, 2009). According to Brown and McNamara (2011), these identities are "produced” at the intersection of individuals’ personal aspirations (in this case regarding mathematics education) and "the multiple external demands they encounter” in their mathematical experiences (p. 27).

For many years mathematics educators and researchers have been concerned about sociological issues related to the moral dimension of mathematics education and students’ mathematical identities in a broad sense. Povey and Zevenbergen (2008) highlighted the political, value-laden and moral nature of mathematics education and Skovsmose (1994) has advocated for a critical mathematics education, where mathematics educators critically analyse and address the role that it can play in empowering or disempowering certain students. Skovsmose also suggested that mathematics education should contribute to critical citizenship through using mathematical tools to interrogate issues related to inequity and moral concern. A praxis approach is consistent with these historical perspectives, although the focus is more on

\footnotetext{
${ }^{1}$ It is not within the scope of this article to provide an in-depth discussion of the concept of identity. For a thorough discussion of mathematics education and identity see Brown and McNamara (2011)
} 
the localised practice and action in a site. In this article the focus is on the moral dimension of the action of everyday classroom teaching, however, we acknowledge that to bring about educational reform it is not enough to attend only to the teachers' practices without also attending to organisational structures that affect practice.

In this article, data from interviews and observations with mathematics educators who are both highly regarded and exemplary have been used to identify and explore aspects of classroom practice that attend to students’ mathematical identities. I have employed a praxis lens to examine these aspects and discuss the moral dimensions

of teacher decisions and actions, highlighting implications for mathematics teaching that includes the development of students' mathematical identities. Finally, the data have been examined to identify practice architectures that enable or constrain a teacher's capacity for praxis and students’ opportunities to develop robust mathematical identities (i.e., mathematical knowledge, skills and dispositions that will enable them to productively engage and use mathematics).

\section{Praxis}

\section{What is Praxis?}

Praxis is a term that has been defined and used in a variety of ways. Here, praxis is a particular form of practice that specifically emphasises the moral and ethical aspects of the activity of teaching and learning. Of course, it is difficult to conceive of teaching as a practice devoid of a significant and continual moral and ethical facet, but viewing teaching as praxis foregrounds these concerns.

According to Kemmis and Smith (2008), "Praxis is what people do when they take into account all the circumstances and exigencies that confront them at a particular moment and then, taking the broadest view they can of what is best to do, they act' (p. 
4, italics in original). For the educator, this means considering the dual purpose of education namely considering the concerns of each individual student and the long-term interests of society (see Figure 1). Teachers are always making decisions and acting in the moment-by-moment activity of the classroom, but if they are conscious of the moral implications of their actions for both the individual students and the world at large (humankind) that can only be judged historically, then they can said to be engaged in praxis.

$<$ Insert Figure 1 here $>$

While acknowledging that the term praxis can mean different things in different cultural and intellectual traditions (Kemmis \& Smith, 2008), the conceptualisation employed here is grounded in the Aristotelian tradition. Aristotle differentiated between different classes of dispositions (epistēmē, technē, phronēsis) that give rise to different kinds of actions (theoria, poiēsis, praxis). While it is not possible here to discuss praxis in great detail (for a fuller discussion see the book Enabling Praxis (2008) edited by Kemmis and Smith), it is important to highlight that praxis is about acting. Therefore, praxis requires one to be active in the physical world and in making an indelible mark in history. While thinking can be part of action, praxis is not the thought that precedes action - it is the process of changing the world by doing something.

\section{Why Praxis is Important}

Education has a double purpose (see Figure 1) - to develop individuals and to form good societies (Kemmis, 2008). Of course these two purposes are complimentary and the achievement of one is integral to the achievement of the other. In mathematics education this requires the teacher to be attentive to the individuals in their classroom 
and to undertake their practice in such a way that individual students develop strong and healthy mathematical identities. But the second purpose listed above also behoves the mathematics teacher to actively work towards the good of society. This could involve aspects such as promoting an invitational and enabling view of mathematical activity, and using mathematical and statistical techniques to explore significant issues. While a praxis perspective is relevant to teaching in any subject, it is particularly salient for mathematics given the history of people feeling mathematically impoverished and alienated after their schooling (Grootenboer, Lomas \& Ingram, 2008).

Praxis is required because mathematics teaching and education is an ethical practice that requires the teacher to continually make morally-dense decisions both in their preparatory work outside the classroom and in their moment-by-moment interactions in the classroom. Viewing mathematics learning as the development of mathematical identity highlights the broader personal perspectives of both the teacher and the students that are intimately engaged in the process, and so attention to more than the knowledge and skill requirements is demanded. One only needs to scan the plethora of literature, or indeed the common societal perspective, that portrays mathematics as dull, irrelevant, useless and often harmful to see the lingering issues that have emerged for both individuals and society at large from forms of mathematics education that have not been attentive to the personal and moral dimensions of mathematical learning.

\section{Practice Architectures}

While teachers can determine to view and enact their mathematical practice as a form of praxis, the possibilities for action are constrained and afforded by the practice architectures of their field (Kemmis, 2008). Practice architectures are mediating preconditions for practice: 
(1) cultural-discursive preconditions which shape and give content to the 'thinking' and 'sayings' that orient and justify practices;

(2) material-economic preconditions and 'set-ups' (Schatzki, 2002) of material objects which shape and give content to the 'doing' of the practice; and

(3) socio-political preconditions that shape and give content to the 'relatings' involved in practice. (Kemmis \& Grootenboer, 2008)

(These are illustrated below in Figure 2). According to Schatzki (2002), practices, like mathematics teaching, are prefigured because the mediating preconditions - the practice architectures, shape and constrain what thinking, saying, doing, and relating are possible. This is not to say that practitioners cannot transform and develop their practice in new ways, but this is only possible by working within and/or against the prevailing practice architectures. However, it is also the case that if practices are to change, then the associated preconditions of sayings, doings and relatings will also need to change. In short, changing mathematics education also involves changing the practice architectures that constitute it.

<insert Figure 2 here $>$

\section{Praxis and Developing Mathematical Identities}

Developing students' mathematical identities through their school mathematics education is a moral practice (Hargreaves, 2001). The health, richness and quality of the students' mathematical identities have a significant impact on their future opportunities (Grootenboer \& Zevenbergen, 2008), but also for society at large. Currently in Australia (and across much of the Western world) there is concern about diminishing participation in mathematics and the impact of this on the future well-being of 
Australian society (Australian Academy of Science, 2006). Therefore, a praxis approach, that foregrounds a mathematical education that is good for the individual and for the wider community, is needed, because recent history indicates that the mathematical teaching practices that have held sway have not been good for many individuals or, it seems, the broader society.

Students’ mathematical identities are significantly shaped by their mathematics teachers and their classroom practices (Hayes, et al., 2006), and so the knowledge and beliefs that shape their pedagogy are influential. In his seminal work, Shulman (1986) outlined the categories of teacher knowledge that underpin teachers’ practices including pedagogical content knowledge and subject matter knowledge. Rowland, Huckstep and Thwaites (2005) investigated these aspects with a particular focus on mathematics subject knowledge, and they identified four 'dimensions', one of which was “contingency”. Contingency referred to the "classroom events that are almost impossible to plan for” (p. 263), where the teacher has to make decisions by thinking on their feet, and do this in the continuous activity of the lesson. It can be in these immediate situations, where a teacher seemingly responds to a student's idea almost without conscious thought, that students' developing mathematical identities can be vulnerable to unintended harm.

A praxis stance towards mathematics teaching sees the teacher acting by considering their actions as they will be judged historically by the broader outcomes. In particular, this means being aware of the broader learning that occurs in mathematics classrooms - their mathematical identities. This also means paying deliberate attention to the development of students' mathematical knowledge and skills, but also their attitudes, values and emotions, and alongside, the general growth of the students as individuals and members of society. However, this agenda is realised in moment-by- 
moment activity in the classroom - the everyday action that all students experience in their mathematics lessons.

\section{The Study}

The aim of the study was to examine teaching in actual classroom practice, and to ground the ideals in the routine, even mundane, thoughts and actions of teachers and students. The study was conceptualised as a series of related qualitative case studies (Stake, 1995) where the aim was to give rich characterisations of practice/praxis in mathematics education. After an initial in-depth interview, a process of data collection was negotiated with each participant including classroom observations, photostimulated reflective discussions, and follow-up interviews with the participants. Together, the data collected for the 13 case studies provided a rich and comprehensive data set. While the data were gathered as 13 case studies, in this report the data set is considered together to highlight aspects related to praxis.

\section{The Participants}

The participant group consisted of thirteen teachers and mathematics educators from across the educational sectors (see Table 1).

$<$ Insert Table 1 here $>$

The teachers involved had been recognised as exemplary teachers and they were identified through consultation with education leaders and members of the mathematics education community (e.g., one participant had received a national teaching excellence award). The participants came from across Australia and New Zealand, and included teachers from metropolitan areas and regional cities. 


\section{Data Collection}

As mentioned above, a range of data collection processes were employed, but the primary modes were semi-structured interviews and classroom observations.

\section{Semi-structured interviews}

While the data collection for each case study was open to negotiation, all involved an initial semi-structured in-depth interview. The desire for a deep understanding of the participants' praxis meant that this interview focussed on the teachers’ personal philosophies about professional knowledge, attributes and practice, and their perceptions of how their philosophy was enacted in the classroom. These conversational interviews were designed so that the participants could experience them as professional discussions about the nature and meaning of their work and their convictions about mathematical pedagogy. In eleven of the case studies follow-up interviews were used to explore aspects of the participant's practice after lessons had been observed. These observations were often augmented by photographs of moments in the lessons, and artefacts such as student work samples and lesson plans/study programs. All the interviews were audio-taped and transcribed, then returned to the participants for editing and verification to ensure the data accurately reflected their views.

\section{Observations}

At least one lesson was observed for 11 of the 13 participants in the study ${ }^{2}$. Detailed field notes were taken during these observations and these notes were then used for the follow-up interview where aspects of the lesson were explored with the

\footnotetext{
${ }^{2}$ It was not possible to observe the lessons of the other 2 participants because they were based too far away from the researcher
} 
participant. The observations were often enhanced by photographs of salient aspects of the lesson. The photographs were only used for stimulated recall to prompt discussion about the practices captured, and once the interview was complete the photographs were deleted. The advantage of using photographs to stimulate recall is that a series of photographs taken during a lesson requires explanation - there is no commentary attached (Walker, 2002). During these reflective discussions the photographs were examined with the participant, stopping as required to discuss and question aspects of their practice as they emerged.

\section{Findings and Discussion}

The data were analysed by initially reading and re-reading the transcripts in order to note and understand aspects that seemed to relate specifically to a moral dimension of teaching and/or aspects where there appeared to be a heightened opportunity for the development or diminishing of students’ mathematical identities. While there were many themes and ideas evident in the data, in this article the discussion is restricted to the praxis-related issues of developing mathematical identities. Therefore, the themes should not be considered as an exhaustive list, but rather, just the particular issues or factors that emerged from the data. The analysis employed grounded theory techniques (e.g., creating codes and categories, developing themes) in order to identify key themes in the data. Although some of the analytical tools of 'grounded theory' were employed, there was no attempt made to actually develop or find an underlying or generalizable 'theory' to explain the data, but rather the themes that emerged -were used to structure the findings. The findings have been organised under two broad headings: (1) moral and ethical issues in developing mathematical identities; and, (2) the context of developing mathematical identities including practice architectures and the learning environment. The findings are based on 
ordinary everyday classroom teaching because that is the very fabric of students' mathematics education, and so the data and examples are not necessarily groundbreaking or new. The purpose here is to view regular teaching through a 'praxis lens' to highlight the significance of perhaps taken-for-granted aspects of good pedagogy.

\section{Moral and Ethical Issues in Developing Mathematical Identities}

As has been noted, education is a morally dense practice because teachers are regularly required to make decisions, and act upon them, when there isn't necessarily a definitively correct choice (Russell \& Grootenboer, 2008). In the study, students were regularly placed in situations where social interactions were heightened and these situations were morally complex because they involved multiple factors and actors, and many of the significant aspects were intangible and tacit. When these occurred, the teachers needed to help the students negotiate and understand appropriate collaborative behaviours. Group work regularly featured in the classroom observations and was common practice for most of the teachers in this study. It was clear that the teachers saw “social learning” and "moral learning” as integral to, and inseparable from, their mathematics classroom pedagogy. By overtly focussing on the students' identities and facilitating the development of "right behaviour" with their students, the teachers' practice was replete with ethical judgments. By fore-grounding these judgments, the teachers engaged in a form of praxis that embraced broader educational goals while simultaneously developing students’ mathematical identities. This was particularly evident as the teachers dealt with the tension of provoking mathematical growth while caring for the students and guarding their emotions, and these are now discussed. 


\section{Protecting Mathematical Identities while Provoking Uncertainty for Growth}

Throughout the interviews and the lesson observations there were many instances and comments that showed that the teachers related professionally to their students with care, concern and thoughtfulness (as you would expect of any teacher). However, learning mathematics can cause anxiety and stress for many students (Grootenboer, et al., 2008), and the relative thoughtlessness of some mathematics teachers can be a significant factor, so it was noted that the participating teachers were careful to attend to the students' emotions and they appeared to treat the students with respect and courtesy. In general terms, comments like "well done, great effort” and “excuse me having my back to you” illustrate this type of attentiveness, and created a warm and welcoming mathematics classroom. This relationally inviting atmosphere is unfortunately not particularly universal in mathematics classrooms, and consequently many students have historically seen mathematics as cold and uninviting (Cotton, 1993). However, students’ mathematical development requires times of uncertainty and disequilibrium as they face new material or ideas, and this can feel threatening and uncomfortable (Carter, 2008). This means that in mathematical learning situations there can be an inherent tension between protecting students’ (often fragile) mathematical identities and facilitating unease and discomfort so growth can occur. This dilemma is not an unhealthy educational situation as it prevents either extreme prevailing, but navigating the tension requires praxis - it is morally and ethically charged (Russell \& Grootenboer, 2008).

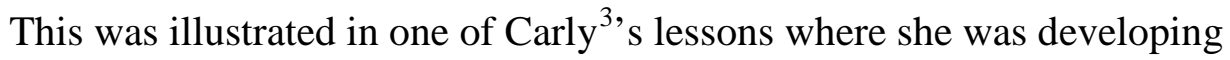
measurement concepts using concrete materials. The instructional part of the lesson began with the teacher using a familiar physical representation, and from this known

\footnotetext{
${ }^{3}$ Pseudonyms are used throughout this report
} 
position she tried to develop the students' understanding of the mathematical concepts involved through manipulating the physical materials and asking thoughtful questions about the various representations. The students then explored the concepts through a range of related examples that moved from the familiar to the unfamiliar. Throughout the lesson several instances were noted were the teacher's actions in the lesson revealed care and concern for the students' developing mathematical identities. For example, one task involved the students cutting a composite shape into smaller regular shapes, and then rearranging them into a rectangle so the area could be calculated. One boy was struggling to rearrange the pieces into the larger rectangle, and the easier option for Carly would have been to simply show the boy how to do it, but instead she spent quite a bit of time encouraging him, praising him for his perseverance, and asking him questions about his actions. Eventually (after about 5 minutes) the boy made the rectangle, and he was quite excited with his success. After the lesson Carly said:

I guess it is just part of who I am - I want the students to feel safe and valued so they can try new and difficult things, and I guess I just give them little reassuring words or a touch on the shoulder without really thinking about it.

This concern did not allow students to avoid engaging with new and deep mathematical ideas, but it did mean that they were supported emotionally and socially as they did. Ascertaining and responding to the tension between challenge and support with a diverse group of mathematical learners' demands a praxis approach to teaching, because the moment-by-moment decisions and actions can have long-term consequences.

A simple way that Carly (and the other participating teachers) supported the students was through regular words of affirmation and encouragement (see quotation above). This is not a revolutionary pedagogical technique, but nevertheless, it is integral to sustaining an invitational learning environment. However, it also needs to be seen as 
sincere and genuine by the students and this occurs when the professional relationships between the teachers and the students are well-formed and solid. In the preceding example, Carly did not just say “well done” or “great', but she praised specific behaviours or traits, including perseverance and thoughtfulness.

Many of the teachers in the study regularly used humour to build rapport with the students while promoting a sense of intellectual adventure. At one point Murray presented a situation that clearly perplexed many of the students and they seemed reluctant to offer any responses, to which he said;

Come on - have a go! What have you got to lose? It's only your career and your future at stake!

Perhaps the humour here is lost because 'you had to be there', but the students responded with genuine mirth, and then a number of students appeared willing to "have a go" and engage with the mathematical ideas at hand. Murray also mentioned the importance of connection through humour, and he suggested that "his bad jokes were an important part of his teaching persona”. Furthermore, apart from making the classroom environment more friendly, humour also enabled the students to see mathematics in a more 'human' way. For many students, mathematics is seen as cold, hard and absolute (Cotton, 1993), and therefore, their learning opportunities are restricted and inequities emerge. Humour, at least for some mathematics teachers, is a way of presenting mathematics in an inviting way to facilitate positive mathematical identities.

In another lesson, Louise followed her students’ attempts to solve a challenging problem by not only responding to their mathematical thinking, but also to their emotions in the learning situation. For example, she asked one student "does it worry you that it's not even?” It is important to note here that she did not try and rescue them from the difficult learning situation by giving them the answer or overly structuring 
their attempts, but she did acknowledge the discomfort or "worry" they were experiencing while encouraging them to persevere and fore-grounding participation rather than the 'right answer'.

Leaving children to struggle with a mathematical concept or task is often not easy for a teacher, but in the process of rescuing them the teacher can also be robbing the students of the mathematical thinking and potential learning (Carter, 2008). Therefore, part of a robust mathematical identity is the resilience to persevere with mathematical tasks when the solution is not readily obvious and grapple with difficult mathematical concepts when understanding is not immediate. For teachers it can be a difficult emotional and ethical practice to allow the students to experience the shortterm distress of the activity for the long-term gain of a robust mathematical identity. To walk the fine line of challenge that builds a resilient mathematical identity requires teacher praxis that is grounded in a deep understanding of the mathematical demands of the task or concept, and relationships with the students that allow him/her to know their capacity for unease in that learning context.

\section{Catering for All Learners}

Another important aspect that emerged from the data was the need to cater for all learners in the mathematics classroom. In the observed lessons there were times when the teachers were working with a whole class, several groups, or 25-30 individuals. It is not uncommon for mathematics classroom programs to either ignore the range of learners in the room by having a linear strategy that is aimed at a general level, and/or to have streamed classes so the student capability within the class is seen to be homogeneous (Boaler, 1997). When teachers pitch their mathematics lessons at the middle, those who might be struggling are left more bewildered, and the students who are more capable can become bored and disinterested. 
In Kristy’s lesson there was a period when the students worked on some simple “quick-revision” questions and they were trying to improve their "speed and accuracy”. This appeared to be a regular activity to begin his mathematics lessons. While this was not an uncommon event in a mathematics class, through some simple strategies the teacher showed an appreciation for the diversity within his class. The students each noted their own time for the task in their books (so they had a chronological account of their times over the year). The teacher then asked the students to compare their times to their previous times. The important aspect to note is that each student was not comparing themselves to other learners in the class; they were comparing their performance with their own previous achievement. The teacher never asked students to publicly declare their times, she only asked if they thought they were "improving or about the same”. To some this may seem like a rather ordinary aspect of the teacher's practice to highlight, but it is in these regular and routine matters that thoughtful attention is required because it can be these moments that are significant for students. Too many students have developed fractured mathematical identities by being publically humiliated in simple activities like the one outlined above, where their performance (and mathematical ability) is publically compared to their classmates and they feel shamed, inadequate and embarrassed.

Student diversity was also catered for by the participants in the activities they employed. A group-based pedagogy was used by many of the teachers in this study, and within this approach the group functioning and outputs were required at both a corporate and individual level. The group functioned best when the students used their diverse skills, knowledge and understandings to work on the task. Therefore, rather than seeking homogeneous groups, often students with diverse abilities, interests and skills were grouped, and the tasks were such that each student had something valuable to 
contribute. For example, in Levi’s lesson he placed the students in groups of three and each student had a particular part to play. These roles were all non-trivial and each had a cognitive element. After the lesson he commented on this pedagogical arrangement;

I don't want anyway to have a job like ‘equipment-getter' or 'time-keeper', so I have no more than three in a group. That way everyone is needed and no-one can just be slack. ... They [the students] all have to be involved in the mathematical thinking of the problem.

This had distinct benefits for the development of students' mathematical identities because they all had to be involved in the cognitive labour of the lesson and more than just knowledge recall or algorithmic proficiency was required (Grootenboer \& Zevenbergen, 2007). This meant that students were exposed to, and had the opportunity to develop, mathematical identities that were broader and well-rounded, as they listened, discussed and debated their shared thinking and solutions.

However, it is important to note that group-based work will not necessarily lead to more robust student mathematical identities unless the pedagogy and tasks are developed specifically for group investigation, as was noted by Levi. Furthermore, a teacher can face particular social dilemmas in a class that is structured around groups, and these require wisdom and tact from the teacher. These are not peculiar to mathematics education, but they do demand praxis so all students feel supported and secure, and group members learn how to behave appropriately and morally when working with others. In a post-lesson interview with Heidi, she reflected;

He is not the easiest person to deal with in a group. Actually, he can be pretty annoying. But then, they [the other group members] are so good, aren't they? ... They try and involve him. They try to work out the best way to approach him, and you could see [referring to a photograph from the lesson] there they gave him a job. 
The group context brings students' broader identities to the fore meaning that there is great scope for growth and development, but conversely, there is similarly heightened potential for damage and harm. While a teacher has control over their own interactions with students, they have less influence over the interactions between students, and so they are often faced with a range of decisions that are moral in nature. These decisions are often 'in the moment' and include knowing when to intervene in group situations. In the above situation, the teacher had to decide before the activity whether to include the particular student (a decision that had to be made before the event), and then while monitoring the group (while all the other groups are working), whether to act to protect the boy's identity or maintain the educational value of the task. These are difficult decisions, and actions (or inaction) that cannot be undone, and the real-time nature of teaching means the decisions have to be made on the spot, with little time for reflection or consideration. This is why praxis is required. In the example, the teacher knew to monitor the group, but she chose not to intervene, and she also decided to trust the other students to act rightly in that situation. In hindsight, it appears she made good decisions and the students' responded in an appropriate manner, but there were no guarantees that this would be the case. While this is not peculiar to mathematics, it highlights the broad educational function of developing students' moral and social identities.

Finally, a number of the participants in the study discussed the importance of catering for diversity by employing mathematical tasks that have multiple solutions and/or multiple solution pathways. Levi commented;

We don't always know the answers to the problems we choose, so we're all in it together. We find they are the better ones to do, where the path [is unclear]. That way, you are not trying to guide them down that pre-set path where you want them to go. You want them to take their own idea and that is why one group will often 
come up with a technique for doing it, and someone else will be completely different, but that's exactly what you want. ... After a while they know that their product is appreciated, whatever they come up with.

What was apparent was the teachers' focus on the processes and the included mathematical thinking rather than just the product. In the classroom characterised by the tasks and associated pedagogy outlined above, students are encouraged to contribute their thoughts, ideas and strategies because the single end-product is de-emphasised. Also, tasks with multiple solution pathways not only cater for a range of students, but they also enhance the intellectual quality of the afforded learning by requiring students to analyse and evaluate the alternatives presented in their group (Freedman, Delp, \& Crawford, 2005).

It was interesting to note that the participating teachers were often deliberately ignorant of the solutions and all the solution pathways. This indicates a move away from the traditional teacher role as expert.

If I know the answer then I can't help myself - I'll tell them. Then they won't do any mathematical thinking, they will just wait for me to give it to them. (Josiah)

This requires the teacher to be secure in their own mathematical and professional identity because they will inevitably have to respond to the mathematical ideas generated through the activities as they arise in the course of the lesson (Grootenboer \& Zevenbergen, 2008). However, by choosing not to know all the answers, the teachers can more genuinely engage in the generative mathematical processes and avoid the temptation to short-circuit student learning by prematurely sharing 'the correct answer'. This is a praxis-orientation to tasks because it sacrifices the teachers' certainty and security so that there are more opportunities for students to develop robust mathematical identities. 


\section{Praxis and Decision-Making}

As has been noted often in this article, praxis is required in the classroom because teachers have to make regular and significant decisions, and then act upon those decisions, throughout the course of their lessons. A teacher can plan learning experiences and arrange the physical parameters of the classroom, but it is the 'on-yourfeet' thinking and reacting that is critical to the success of the lesson (Rowland et al., 2005). Obviously this requires a teacher with a strong professional pedagogical identity. But, this responsive pedagogy also requires a teacher whose mathematical identity is robust, because they need the discipline-based resources to see the mathematical opportunities evident in any learning moment, and mathematical knowledge and insight to give appropriate responses (Grootenboer \& Zevenbergen, 2008). Thus, to be able to make sound decisions and then to act accordingly, mathematics teachers need to have well-developed mathematical identities and solid pedagogical identities. Peter discussed how this might be practiced.

\footnotetext{
It's a hard balance, sometimes they get a problem and some kids think that I'm here to answer their question and I guess that I try to make sure the kid does have an idea of what they need to do and where they need to go. Sometimes I think they need a different angle so I give them a different question if the question I asked they're not making any progress on it so sometimes I'll say I want you to think about a different question and that allows them to move their thinking forward. Once I hear them and see what they have done I try and make a quick decision based on what I know about them, and the demands of the problem
}

It is probably not new that teaching largely involves moment-by-moment decisionmaking and acting, but the preceding quote does highlight the critical nature of the teachers' identity because responses and actions are required 'immediately' and a teacher does not often have the opportunity to reflectively consider them. The quote reveals that mathematical pedagogy should be responsive to student needs and the 
learning opportunities that arise in the course of a lesson. In this instance this pedagogy derived from the personal qualities and attributes that Peter displayed. He was prepared to work with his students and be in error if it meant that the student would learn.

\section{Students’ Personal Development}

While the focus here is mathematics learning, students also develop in a broader sense while engaging in their mathematics education program. This development is not the overt focus of mathematics lessons, but nevertheless, it is a significant and important part of their education. Therefore, it is part of their mathematics education and the development of their identity. Furthermore, it is occurring whether it is overtly considered or not, and so it seems important that it is given some attention. A praxis approach sees deliberate attention given to students’ broader personal development, including moral, ethical and social learning.

Group work was a significant theme in the data and this was addressed previously. However, in employing a group-based pedagogy, students are also given the opportunity to develop their capacity to work collaboratively. This was illustrated in Nick’s data. He commented:

If you don't like somebody's idea, how do you go round that in a way that it doesn't offend that person, and how do you bring all those ideas together? Because, in the end, it's about giving them all those techniques, because you can't just expect them to be able to go to a group and just know those things. It's just something they don't know, so therefore the modelling of it is probably one of those things that we do do.

Here he has highlighted his role as a mathematics teacher in developing students' collaborative skills, including respectful communication. It is also clear that this is something he taught through various approaches including teacher modelling. Further in the interview, he added the democratic processes he employed when they, as a whole 
class, discuss student responses to group mathematical tasks. Here again, Nick firstly showed the students that all of their responses are valued and, secondly, he modelled that democratic processes can be used to negotiate with others. These are an integral part of a critical mathematics education (Skovsmose, 1994). Furthermore, the pedagogical structures employed in his mathematics class also provide meaningful opportunities for students to develop morally as they engage in social learning experiences.

\section{The Context of Developing Mathematical Identities}

No teaching occurs in a vacuum, and so the teachers' practice in developing their students' mathematical identities is always contextual. The context includes the practice architectures that are generally beyond the teachers' control, but also aspects of the context are created by the teachers as they seek to develop appropriate learning opportunities. In many respects, the practice architectures limit the range of possibilities the teacher can use in the teaching, and the particular learning structures and events are what the teacher creates within the limitations.

\section{Practice Architectures}

It was clear that the participating teachers were constrained by practice architectures that created affordances for certain pedagogical activities and limitations of others. The practice architectures include physical parameters such as the teaching space available, but perhaps more importantly, they also include of a number of regulatory requirements that certainly frame (e.g., government curriculum/syllabus) and impinge (e.g., mandatory external testing of students) upon the teachers’ professional practice. 
One of Murray's observed classroom episodes opened with the students doing a "basic skills" timed test. In this part of the lesson the students were given a sheet with 100 arithmetic questions (e.g., $23+58,43$ x 14) that progressively got more difficult. These questions they completed in silence on their own at their desks. The students were required to do as many as they could in four minutes. The teacher stated that the goal of this activity was "speed and accuracy", and once it was completed the students marked their work with a red pen as the teacher quickly read out the answers. Murray then proceeded with the main part of the lesson which was student-centred and investigative in nature and that focussed on conceptual development through hands-on activities. The activity involved the students examining three-dimensional objects and their nets. What was striking was the stark contrast between the traditional and formal start to the lesson and the relaxed and relatively innovative pedagogy that followed, but this disjuncture did not appear to be obvious to the teacher concerned. A sound mathematics education program needs to address procedural and conceptual elements (Gray \& Tall, 1994), and so the issue was not so much about the content, but it was the radically different conceptions of how children learn mathematics, the mathematical epistemology, and the classroom atmosphere that imbued each part. In the interview that followed the observation, the difference between the two parts of the lesson was raised, but the contradiction appeared to be unproblematic to the teacher. Murray commented:

I thought the lesson flowed nicely and the kids went into the activity quickly. They didn't seem too worried about the testing - they know we just have to do that stuff and that's ok with me.

It is possible that there were external factors that caused Murray to employ such an introduction to his lesson, but despite some interview probing, he seemed largely 
unaware of them. Perhaps the pressure of external testing around students' basic mathematical skills has meant that teachers feel constrained to practice these in a testtype environment on a regular basis (i.e., every day). In order to accommodate this practice, they 'tack on' a traditional timed skill test to the beginning of each lesson so they can then get on with their regular program. It could also be that the less tangible practice of tradition and expectation see this activity emerge in the pedagogy of an innovative mathematics teacher. It could also be that Murray has successfully learned how to traverse the often conflicting architectures that confront his day to day practice. Indeed, Kristy noted in the interview that there is a tension between teaching students certain mathematical skills and enabling them to think mathematically.

\footnotetext{
You know you are always trying to cover the curriculum and to teach all the stuff that you have to do, but then you sit back and realise that they really aren't getting the big picture. They do all these little maths things but they don't get a chance to think and see maths in a broader way.
}

Tradition and external testing tends to demand certain mathematical products and the reproduction of set procedures, and these can be in tension with more innovative-type approaches as have been advocated by Boaler and Staples (2008) and through the productive pedagogies (Lingard, et al., 2001). This tension requires a praxis-based approach to pedagogy because the teacher is negotiating their teaching actions between somewhat competing agendas.

\section{Praxis and Pedagogical Structures}

The teachers in the study chose and developed their learning structures including group and individual work. Group-work was seen as an important and integral feature of Katherine’s (and several other participating teachers) mathematical pedagogy 
because she believed it promoted good mathematical learning, and it also facilitated the development of students' social skills and thoughtful behaviours.

I like to use groups when I can, as long as I don't get behind. The students can have a go at more complex problems in a group because they bring all their brains and experiences to it. ... and they have to learn to negotiate, and listen, and take turns. All important things to learn

The frequent and regular use of group-work by Katherine was seen as an effective way to facilitate the development of the students' identities in the broader sense (i.e., as good citizens), while at the same time promoting particular development in their mathematical identities. In this way, her teaching is a form of praxis in that she deliberately attends to the two-broad goals of education - the improvement of individuals and of the community as a whole (Kemmis, 2008). Her decision to use group-work was not an arbitrary decision but a deliberate pedagogical practice to promote better mathematical learning and a better community by facilitating the concurrent development of social skills

When students' learning is focussed on particular discipline-based areas (such as mathematics), they are also learning about many other things that may be planned or incidental, including affective aspects that significantly influence the development of their mathematical identity (Zevenbergen \& Grootenboer, 2009). Therefore, effective pedagogy takes into account the broader learning of the students as a pragmatic and ethical imperative. Of course, the use of group-work does not in and of itself guarantee students will develop healthy mathematical identities, and so the teachers’ group-work praxis had certain characteristics including explicit teaching about how to work in a group, democratic processes, and authentic collaboration. This was illustrated when one of the teachers reflected 
... they are just so good at it, that they know that the big thing in the group is respecting each other and respecting their ideas, and therefore, they have learnt to know when it is time to step in. But often you see it ... when we come through, we might change each term, the people they are working with, and it takes them a while to work out, ‘How do I deal with these new people that I haven’t worked with in a group on a problem?' And they have to learn going about how to approach this person, to say, 'I don't really like what you are doing, and shall we go about it in another way.' And at the beginning of term we will change their groups, it takes them a while to bring them back to the values that we are talking about. (Eleana)

The participating teachers valued and paid attention to the students' social and moral development in their teaching of mathematics. The use of group-work also meant that the students developed a more robust mathematical understanding because they had to express their thoughts and ideas, and defend and negotiate their understandings.

It is important to note that, although group work was commonly employed and promoted by many of the participating teachers, there were others who primarily used an individual, desk-based arrangement. For example, Elijah’s class was organised in rows and columns of individual desks and the pedagogy was teacher directed and ‘traditional' in nature. While Elijah's class was quite different from many of the other teachers, it is important to note that his motivation and reasoning for doing so were in many ways similar to the other participants. In his interviews he talked about "helping the students to develop good values” and "competence and confidence in mathematics”, and his pedagogy was consciously undertaken to promote these goals. Throughout Elijah’s interviews it was clear that the ethical dimension of his practice weighed heavily on his mind, and therefore, his mathematics teaching was a form of praxis, despite it appearing to be quite different in practice from what many might perceive as fashionable pedagogy. 
It is a big responsibility teaching these kids maths, especially those who are on the edge of giving up. I've got to keep them hooked-in and wanting to come, but I've also got to challenge them and make sure they learn the content. It can be difficult and I can be tough on them, but I try and think about what they really need.

\section{Conclusions}

A praxis understanding of teaching foregrounds the ethical and moral dimensions of education. Mathematics education has a history of alienating and disenfranchising many learners so it is now common for many people to have a poor attitude towards the subject and to avoid engaging with mathematical experiences (Cotton, 1993, Grootenboer, et al., 2008). The long-term damage wrought in mathematics classrooms sees a majority of people exiting school with mathematical identities that are incapacitated and this in turn limits their life opportunities. Given these pervasive outcomes of mathematics education, clearly mathematics teaching is a practice that is highly ethical, and hence there is a need to foreground this dimension. This also requires a greater focus on the person and identity of the teacher. Therefore, teachers need to see their professional practice as a form of praxis where they overtly consider the ethical, moral and affective dimension of their pedagogy.

In this article the focus has been on aspects of the participating teacher's work that was rather ordinary and seemingly routine, and this was deliberate because this is the very mathematics education students experience day in, and day out, in regular mathematics classrooms. Therefore, it is suggested that it is this everyday practice that needs attention if mathematics education is going to be improved. Furthermore, while I do not want to diminish the need to focus on pedagogical skills, knowledge and resources, there is also a need to centre more broadly on the identity of the teacher (Palmer, 1998). Teachers of mathematics are in a powerful position because they can significantly impact on the mathematical identity and the futures of learners through the 
nature of the relational pedagogy they practice in their classrooms. This is evident throughout the everyday, routine mathematics classes that the teachers and students experience.

While there are many difficult decisions teachers need to make as they engage in the moment by moment practice of teaching mathematics, particularly salient ones relate to balancing challenge and support. This was evident in this study where at times the teachers chose to let students struggle with a mathematical idea and grapple with the concepts at a deep level, and yet at other times they released the pressure. How and when to intervene around these issues are critical in the development of students' mathematical identities. Students need to engage in deep mathematical ideas to develop their mathematical competence and understanding, but they can’t be left to struggle so they become disillusioned and lose their confidence. There is no clear-cut 'recipe' about how to respond in these situations. These sorts of decisions require praxis. The teacher needs to have a personally well-developed mathematical identity so that they can see the mathematical potential of any particular learning situation. They also need to have warm and deep professional relationships with their students so that they know when a learner needs extra support and when they can be left to grapple with the ideas.

\section{References}

Australian Academy of Science. 2006. Mathematics and statistics: Critical skills for Australia's future. The national strategic review of mathematical sciences research in Australia. Canberra, ACT: Author.

Boaler, J. 1997. Experiencing school mathematics: Teaching styles, sex and setting. Buckingham: Open University Press.

Boaler, J., and M. Staples. 2008. Creating mathematical futures through an equitable teaching approach: the case of Railside school. Teachers College Record 110: 608-645. 
Brown, T., and O. McNamara. 2011. Becoming a mathematics teacher: Identity and identifications. Dordrecht: Springer.

Carter, S. 2008. Disequilibrium and questioning in the primary classroom- Establishing routines that help children learn. Teaching Children Mathematics 15: 134-137.

Cotton, T. 1993. Children's impressions of mathematics. Mathematics Teaching 143: 14-17.

Freedman, S.W., V. Delp, and S.M. Crawford. 2005. Teaching English in untracked classrooms. Research in the Teaching of English 40: 62-126.

Gray, E. M., and D. O. Tall. 1994. Duality, ambiguity, and flexibility. Journal for Research in Mathematics Education 25: 116-140.

Grootenboer, P., G. Lomas, and N. Ingram. 2008. The affective domain and mathematics education. In Research in mathematics education in Australasia 2004-2007, ed. H. Forgasz, A. Barkatsas, A. Bishop, B. Clarke, S. Keast, W. T. Seah and P. Sullivan, 255-269. Amsterdam: SENSE Publishing.

Grootenboer, P., T. Smith, and T. Lowrie. 2006. Researching identity in mathematics education: The lay of the land. In Identities, cultures and learning spaces (Proceedings of the $29^{\text {th }}$ annual conference of Mathematics Education Research Group of Australasia), ed. P. Grootenboer, R. Zevenbergen, and M. Chinnappan, 612-615, Canberra, Australia: MERGA.

Grootenboer, P., and R. Zevenbergen. 2007. Identity and mathematics: Towards a theory of agency in coming to learn mathematics. In Mathematics: Essential research, essential practice (Proceedings of the 30th annual conference of the Mathematics Education Research Group of Australasia), ed. J. Watson and K. Beswick, 335-344). Hobart, Australia: MERGA.

Grootenboer, P., and R. Zevenbergen. 2008. Identity as a lens to understand learning mathematics: Developing a model. In Navigating currents and charting directions (Proceedings of the 31st annual conference of the Mathematics Education Research Group of Australasia), ed. M. Goos, R. Brown and K. Makar, 243-250). Brisbane: MERGA

Hargreaves, A. 2001. The emotional geographies of teaching. Teachers' College Record 103: 1056-1080.

Hayes, D., M. Mills, P. Christie, and B. Lingard. 2006. Teachers and schooling making a difference: Productive pedagogies, assessment and performance. Crows Nest, NSW: Allen \& Unwin. 
Kemmis, S. 2008. Praxis and practice architectures in mathematics education. In Navigating currents and charting directions (Proceedings of the 31st annual conference of the Mathematics Education Research Group of Australasia), ed. M. Goos, R. Brown and K. Makar, 17-28, Brisbane: MERGA

Kemmis, S. 2009. 'Research for praxis’. Keynote address at Petra Ponte Inaugural Symposium Utrecht University of Applied Sciences, October 7.

Kemmis, S., and P. Grootenboer. 2008. Situating practice. In Enabling praxis: Challenges for education, ed. S. Kemmis \& T. J. Smith, 37-62, Amsterdam: SENSE Publishing.

Kemmis, S., and T. Smith. 2008. Personal praxis: learning through experience. In Enabling praxis: Challenges for education, ed. S. Kemmis \& T. J. Smith, 15-36, Amsterdam: SENSE Publishing.

Lingard, R., J. Ladwig, M. Mills, N. Bahr, D. Chant, M. Warry, et al. 2001. The Queensland school reform longitudinal study. Brisbane: Education Queensland.

Palmer, P. 1998. The courage to teach: Exploring the inner landscape of a teachers' life. San Francisco: Jossey-Bass

Povey, H., and R. Zevenbergen. 2008. Mathematics education and society: an overview. In The first century of the international commission on mathematical instruction (1908-2008): Reflecting and shaping the world of mathematics education, ed. M. Menghini, F. Furinghetti, L. Giacardi \& F. Arzarello, 277-288, Rome: Istituto della Enciclopedia Italiana.

Rowland, T., P. Huckstep and A. Thwaites. 2005. Elementary teachers’ mathematics subject knowledge: The knowledge quartet and the case of Naomi. Journal of Mathematics Teacher Education 8: 255-281.

Russell, H. and P. Grootenboer. 2008. Finding Praxis? In Enabling praxis: Challenges for education, ed. S. Kemmis \& T. J. Smith, 109-126, Amsterdam: SENSE Publishing.

Schatzki, T. 2002. The site of the social: A philosophical account of the construction of social life and change. University Park, Pennsylvania: University of Pennsylvania Press.

Schulman, L. S. 1986. Those who understand, knowledge growth in teaching. Educational Researcher, 15, no. 2: 4-14.

Skovsmose, O. 1994. Towards a critical mathematics education. Educational Studies in Mathematics, 27: 35-57. 
Stake, R. 1995. The art of case study research. Thousand Oaks, CA: Sage.

Walker, R. 2002. Case study, case records and multimedia. Cambridge Journal of Education 32: 109-127.

Zevenbergen, R and P. Grootenboer. 2009. Towards a theory of identity and agency in coming to learn mathematics. Eurasia Journal of Mathematics, Science \& Technology Education 5:, 255-266 